Article

\title{
Fractionation of Biomolecules in Withania coagulans Extract for Bioreductive Nanoparticle Synthesis, Antifungal and Biofilm Activity
}

\author{
Murtaza Hasan ${ }^{1,2, *,+} \oplus^{\mathbb{D}}$, Ayesha Zafar ${ }^{2,+}$, Irum Shahzadi ${ }^{2}$, Fan Luo ${ }^{1} \mathbb{D}$, Shahbaz Gul Hassan ${ }^{3}$, \\ Tuba Tariq ${ }^{2}$, Sadaf Zehra ${ }^{4}$, Tauseef Munawar ${ }^{5}$, Faisal Iqbal ${ }^{5}$ and Xugang Shu ${ }^{1, *}$ \\ 1 College of Chemistry and Chemical Engineering, Zhongkai University of Agriculture and Engineering, \\ Guangzhou 510225, China; luofan01@21cn.com \\ 2 Department of Biochemistry and Biotechnology (Baghdad-ul-Jadeed Campus), The Islamia University of \\ Bahawalpur, Bahawalpur 63100, Pakistan; ayeshazafar510@gmail.com (A.Z.); s.irum66@gmail.com (I.S.); \\ tubatariq222@gmail.com (T.T.) \\ 3 College of Information Science and Engineering, Zhongkai University of Agriculture and Engineering, \\ Guangzhou 510225, China; mhasan387@gmail.com \\ 4 Department of Botany, The Islamia University of Bahawalpur, Bahawalpur 63100, Pakistan; \\ sadaf.zahra@iub.edu.pk \\ 5 Department of Physics, The Islamia University of Bahawalpur, Bahawalpur 63100, Pakistan; \\ rana.tuseefmunawar@gmail.com (T.M.); faisal.iqbal@iub.edu.pk (F.I.) \\ * $\quad$ Correspondence: murtaza@zhku.edu.cn (M.H.); xgshu@21cn.com (X.S.); Tel.: +86-020-8900-3114 (X.S.) \\ + These authors contributed equally to this work.
}

Academic Editor: Giovanni Benelli

Received: 5 June 2020; Accepted: 20 July 2020; Published: 31 July 2020

\begin{abstract}
Withania coagulans contains a complex mixture of various bioactive compounds. In order to reduce the complexity of the plant extract to purify its phytochemical biomolecules, a novel fractionation strategy using different solvent combination ratios was applied to isolate twelve bioactive fractions. These fractions were tested for activity in the biogenic synthesis of cobalt oxide nanoparticles, biofilm and antifungal activities. The results revealed that plant extract with bioactive fractions in $30 \%$ ratio for all solvent combinations showed more potent bioreducing power, according to the observed color changes and the appearance of representative absorption peaks at $500-510 \mathrm{~nm}$ in the UV-visible spectra which confirm the synthesis of cobalt oxide nanoparticles $\left(\mathrm{Co}_{3} \mathrm{O}_{4} \mathrm{NPs}\right)$. XRD diffraction was used to define the crystal structure, size and phase composition of the products. The fractions obtained using $90 \%$ methanol/hexane and $30 \%$ methanol/hexane showed more effectiveness against biofilm formation by Pseudomonas aeruginosa and Staphylococcus aureus so these fractions could potentially be used to treat bacterial infections. The $90 \%$ hexane $/ \mathrm{H}_{2} \mathrm{O}$ fraction showed excellent antifungal activity against Aspergillus niger and Candida albicans, while the 70\% methanol/hexane fraction showed good antifungal activity for $C$. albicans, so these fractions are potentially useful for the treatment of various fungal infections. On the whole it was concluded that fractionation based on effective combinations of methanol/hexane was useful to investigate and study bioactive compounds, and the active compounds from these fractions may be further purified and tested in various clinical trials.
\end{abstract}

Keywords: fractionation; reducing activity; biomolecules; antibiofilm; microbial infection

\section{Introduction}

Adverse increases in the rates of microbial, fungal and viral infections worldwide prompted by compromised and human immunity are due in part to the indiscriminate use of antibiotics that 
enhances resistance in microbial communities against the corresponding antigens [1]. The generation of biofilms by microbes, which root in a self-produced matrix on living and non-living surfaces [2], is a peculiar behavior of microbes in inducing and producing resistance. Biofilm affinity is associated to a firm attachment of the microbe and biofilm-forming microbes have a great tendency to stick permanently to the large variety of surfaces [3]. These tiny creatures' biofilms are protected by a layer of exopolysaccharides, which can be up to 1000 times more resistant to antimicrobials, which has increased exponentially the rate of chronic infections caused by increased resistance against the host immune system and antibiotics [4,5]. Among such microbes is Candida albicans, a well-known resistant nosocomial bacterium primarily known for being the main cause of infectious diseases [6] such as oral thrush [7], vaginitis [8] organ transplant recipients [9] and forms of cancer in HIV/AIDS patients. Besides resistance, the limited availability of commercial drugs effective against bacteria and the resulting toxicity has increased the global rate and effects of infections in people. This severe problem has driven the interest of researchers in developing less toxic, herbal bioactive compounds that could work against such strains of microbes. Similarly, the commonly known resistant fungus, Aspergillus species, responsible for pulmonary diseases, has also acquired resistance to many common drugs [10]. In order to overcome these biofilm-producers alternative treatments include the use of antibiofilm agents produced by medicinal plants as this mode of action reduces the resistance susceptibility [11]. Plants, being an enriched source of naturally occurring biologically active components, play a vital role in the prevention and treatment of diseases by boosting immunity and reducing toxicity [12,13]. Ancient plants like W. coagulans contain many useful bioactive molecules such as withanolide, withaferin, withacoagin [14], etc., that have been used to synthesize therapeutic drugs for the prevention and treatment of various diseases due to their reduced side effects $[15,16]$. W. coagulans belongs to the Solanaceae, a family of common traditional therapeutic plants with wide range of pharmacological applications [17], including antimicrobial, anti-inflammatory [18], antitumor [19], antihyperglycemic [20], cardiovascular, and immunosuppressive properties [21]. The constituents of $W$. coagulans include free amino acids, essential oils, steroidal lactones and esterases, widely used for their pharmacological activities [22]. A few studies have also recommended the use of withanolide, withaferin and other biological entities found in $W$. coagulans for their bioreducing potential in the synthesis of nanoparticles [23,24], and studies have reported the eco-friendly and less toxic preparation of nanoparticles and pharmacological studies using W. coagulans components [25].

So far, all these biological activities were tested using crude extracts containing complex mixtures of active biomolecules and the solvents-based screening, fractionation and functionalization of bioactive compounds has not been previously reported. The development of antibiofilm strategies is a major interest and also the basis of an important field of investigation that is the development of premium, environmentally friendly antibiofilm biomolecules. The present work was focused on investigate the functional role of fractions obtained using methanol and hexane with water and mixtures of methanol and hexane to purified active biomolecules from W. coagulans extract. For this purpose, W. coagulans fractions were extracted with mixtures containing different ratios of methanol and $n$-hexane and water and methanol and $n$-hexane mixtures in order to evaluate the bioactivities such as bioreducing potential for the synthesis of cobalt nanoparticles, and antioxidant, anti-biofilm and antifungal activities.

\section{Results}

The increasing resistance of microbes against antibiotics calls for the urgent discovery of unique biomolecules from extracts of plants like $W$. coagulans that are of potential interest for their antibiofilm and antifungal activity and as bioreducing agents for the synthesis of cobalt oxide nanoparticles $\left(\mathrm{Co}_{3} \mathrm{O}_{4}\right.$ $\mathrm{NPs}$ ). The species $W$. coagulans is highly acclaimed in the Indian ayurvedic system of medicine, where it is known for its medicinal significance in promoting physical and mental health [26,27]. Its active components include alkaloids, steroidal compounds, lactones, withaferin a [28], withanoloids [29], withanone [30], etc. that act as anti-inflammatory, anticancer, chemoprotective, hepatoprotective, immune modulatory, antifungal, antibacterial, hypocholestroemic, and radical scavenging agents [31]. 
The complex bioactive extract of $W$. coagulans contains potent and functional molecules that must be fractionated to simplify the complexity and provide separate bioactive molecules that can exhibit their functionalities efficiently. Different fractions of plant extract obtained using different solvents and mixtures of solvents were used to resolve the complexity of the biological entities of W. coagulans used as bioreducing, antibacterial, antifungal agents [32]. This fractionation route provided a means to separate, simplify and unveil the hidden active molecules in the complex. Initially using a W. coagulans extract, 12 different methanol, hexane and their mixture fractions in ratios of 30\%, 50\%, 70\%, 90\% were made (Figure S1) and their bio-reducing, antibiofilm and antifungal potential in vitro evaluated (Figure 1).

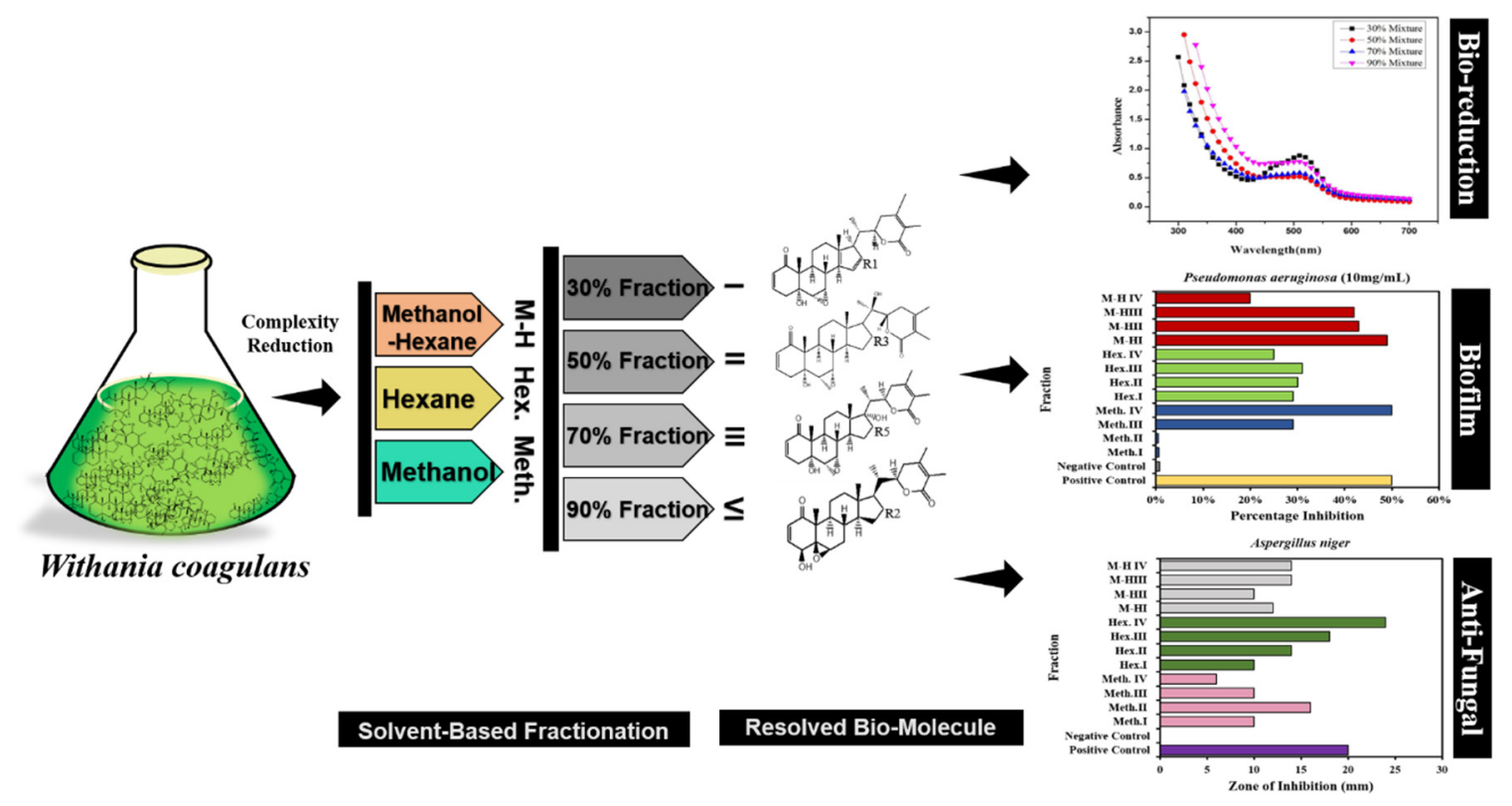

Figure 1. Schematic illustration of $W$. coagulans biomolecules and their applications.

\subsection{Green Synthesis of $\mathrm{Co}_{3} \mathrm{O}_{4} \mathrm{NPS}$}

Pink coloured cobalt chloride solution was mixed individually with all 12 different solvent-based plant extract fractions that turned to a dark brown color upon addition and continuous magnetic stirring at $90^{\circ} \mathrm{C}$ for five $\mathrm{h}$. As the chemical reaction proceeded the color changed from dark brown to light brown indicating the synthesis of $\mathrm{Co}_{3} \mathrm{O}_{4}$ NPs (Figure S2).

\subsubsection{Characterization of Green Synthesized $\mathrm{Co}_{3} \mathrm{O}_{4} \mathrm{NPs}$}

Monitoring the reduction potential of synthesized $\mathrm{Co}_{3} \mathrm{O}_{4}$ NPs by UV spectroscopy using the Withania-based fractions showed different peaks within the 500-510 nm range for different solvent fractions [33]. The methanol and water ratio results conclusively indicated that $30 \%$ methanol/ $\mathrm{H}_{2} \mathrm{O}(3: 1)$ showed the highest peak, indicating that the $30 \%$ fraction was a more active bioreducing fraction than $50 \%$ methanol $/ \mathrm{H}_{2} \mathrm{O}(5: 5), 70 \%$ methanol $/ \mathrm{H}_{2} \mathrm{O}(7: 3)$, or $90 \%$ methanol $/ \mathrm{H}_{2} \mathrm{O}(9: 1)$, as they all showed less bioreducing activity [34,35] (Figure 2a). Among the next four fractions based on hexane and water ratio $30 \%$ hexane $/ \mathrm{H}_{2} \mathrm{O}(3: 1)$ and $90 \%$ hexane/ $\mathrm{H}_{2} \mathrm{O}(9: 1)$ showed almost same highest peak which indicated that these fractions have more bioreducing potential than $50 \%$ hexane $/ \mathrm{H}_{2} \mathrm{O}(5: 5)$ and $70 \%$ hexane $/ \mathrm{H}_{2} \mathrm{O}$ (7:3). Furthermore $70 \%$ hexane/ $\mathrm{H}_{2} \mathrm{O}$ showed a much lower peak with no bio-reducing potential $[36,37]$ (Figure 2b). Similarly, the four methanol/hexane-based fractions with different ratios (30\%, 50\%, 70\%, $90 \%$ ) were evaluated next for bioreducing potential and was indicated that $30 \%$ fraction mixture of methanol/hexane (3:1) showed a much sharper peak indicating better bioreducing potential than $50 \%$, $70 \%, 90 \%$ methanol/hexane fraction mixtures [23,38] (Figure 2c). 

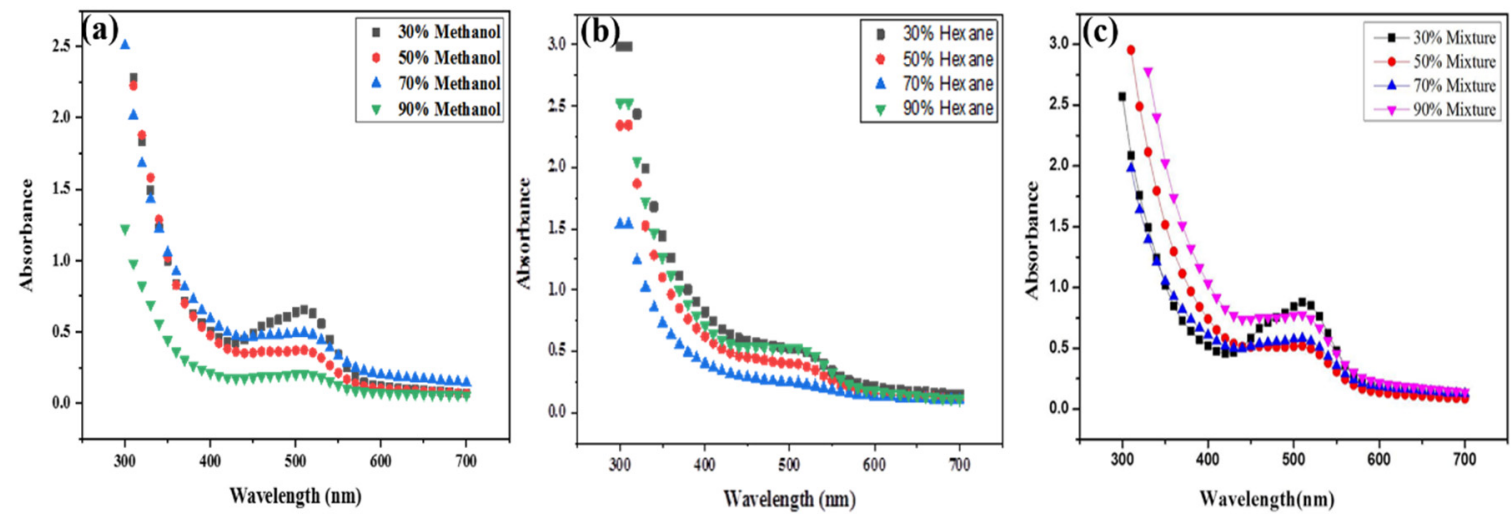

Figure 2. Bioreducing potential of $W$. coagulans based on: (a) methanol (b) hexane (c) methanol/hexane (mixture) fractions for $\mathrm{Co}_{3} \mathrm{O}_{4}$ NPs synthesis.

For optimizing the results a comparative analysis was done between $30 \%$ fraction of methanol/ $\mathrm{H}_{2} \mathrm{O}$, $30 \%$ hexane $/ \mathrm{H}_{2} \mathrm{O}$ and $30 \%$ methanol/hexane and the results demonstrated that out of all mixtures the $30 \%$ methanol/hexane (3:7) fraction mixture showed a much sharper peak. meaning it had a higher bioreducing ability than $30 \%$ methanol $/ \mathrm{H}_{2} \mathrm{O}$ and $30 \%$ hexane $/ \mathrm{H}_{2} \mathrm{O}$ fraction, as seen in Figure 3a.
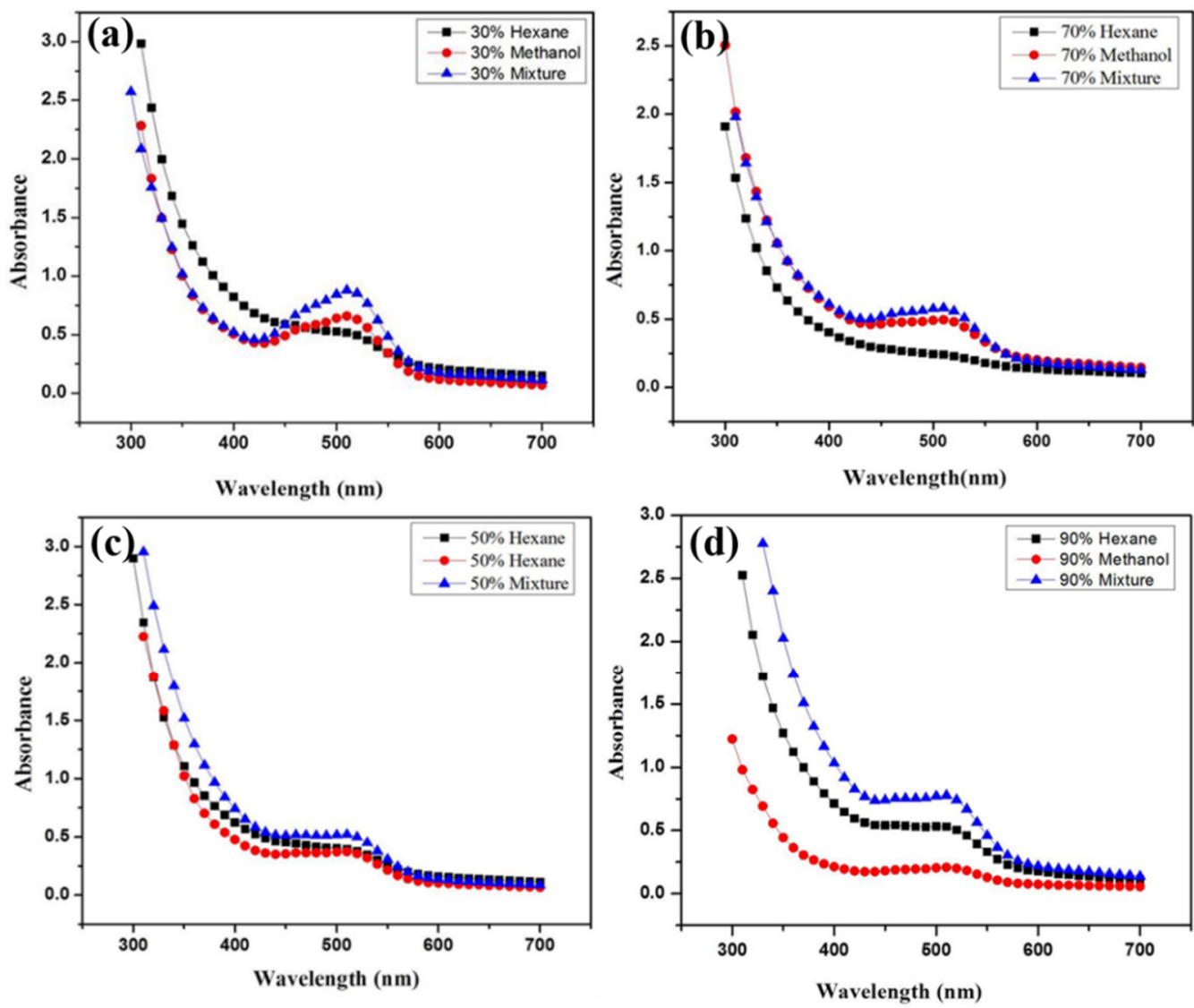

Figure 3. Bioreducing potential of Withania coagulans based on methanol, hexane and methanol/hexane (mixtures) using (a) 30\% fraction, (b) 50\% fraction, (c) 70\% fraction, (d) 90\% fraction.

Among the $50 \%$ fractions, $50 \%$ methanol/hexane (5:5) fraction mixture showed higher peaks corresponding to a higher bioreducing potential than $50 \%$ methanol $/ \mathrm{H}_{2} \mathrm{O}$ and $50 \%$ hexane $/ \mathrm{H}_{2} \mathrm{O}$, but $50 \%$ hexane $/ \mathrm{H} 2 \mathrm{O}$ and $50 \%$ methanol $/ \mathrm{H}_{2} \mathrm{O}$ showed almost the same peak and almost the same bioreducing potential (Figure 3b). 
Next, among the different $70 \%$ fractions of $W$. coagulans, the $70 \%$ methanol/hexane $(7: 3)$ mixture fraction showed a high peak with higher bioreducing potential than $70 \%$ methanol $/ \mathrm{H}_{2} \mathrm{O}$ and $70 \%$ hexane $/ \mathrm{H}_{2} \mathrm{O}$. Here $70 \%$ methanol $/ \mathrm{H}_{2} \mathrm{O}$ showed a much sharper peak (indicating better bioreducing potential) than the $70 \%$ hexane $/ \mathrm{H}_{2} \mathrm{O}$ fraction, as illustrated in Figure 3c. Finally, out of all the $90 \%$ fractions of $W$. coagulans, $90 \%$ methanol/hexane (9:1) fraction mixture showed the highest peak indicating a higher bioreducing potential than $90 \%$ methanol/ $\mathrm{H}_{2} \mathrm{O}$ and $90 \%$ hexane $/ \mathrm{H}_{2} \mathrm{O}$. Here different results were observed because $90 \%$ hexane $/ \mathrm{H}_{2} \mathrm{O}$ shows a much sharper peak than $70 \%$ methanol $/ \mathrm{H}_{2} \mathrm{O}$ meaning that $70 \%$ hexane $/ \mathrm{H}_{2} \mathrm{O}$ fraction has higher bioreducing ability than $70 \%$ methanol $/ \mathrm{H}_{2} \mathrm{O}$ (Figure 3d).

\subsubsection{XRD Analysis of $\mathrm{Co}_{3} \mathrm{O}_{4} \mathrm{NPs}$}

XRD diffraction was used to define the crystal structure and phase composition of the produced NPs. The XRD patterns of the samples obtained with different solvent fraction ratios are presented in Figure $4 a-c$. The observable diffraction pattern of materials obtained using methanol (fraction (a)), hexane (fraction (b)) and methanol/hexane (fraction (c)) were well-matched with $\mathrm{Co}_{3} \mathrm{O}_{4}$. The diffraction patterns of the methanol fraction were thus consistent with JCPDS Card No. 01-080-1534, hexane fraction (b) with JCPDS Card No. 01-074-1657, and methanol/hexane fraction (c) with JCPDS Card No. 01-076-1802, respectively. The peaks and related planes are indicated in Figure 4. The XRD results show that none of the samples have any characteristic peaks due to impurities, which shows that the grown samples have outstanding crystalline nature. The lattice parameters $(a)$ and unit cell volume $(v)$ of the samples were calculated using the following formula:

$$
\begin{gathered}
\frac{1}{d^{2}}=\frac{h^{2}+k^{2}+l^{2}}{a^{2}} \\
v=a^{3}
\end{gathered}
$$
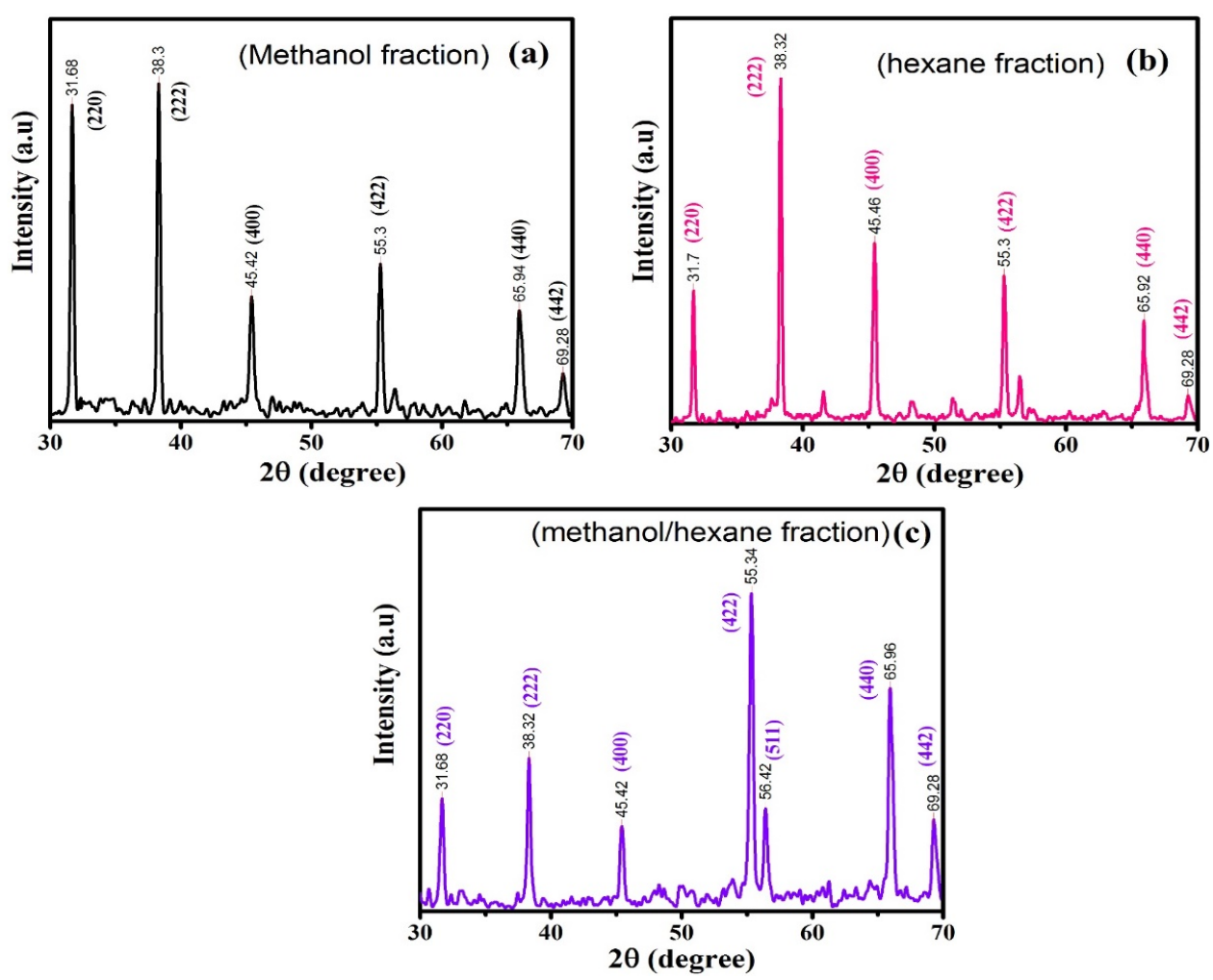

Figure 4. XRD analysis of $\mathrm{Co}_{3} \mathrm{O}_{4}$ nanoparticles based on solvent fractions: (a) methanol fraction (b) hexane fraction, (c) methanol/hexane fraction. 
Where (hkl) are the miller index, ' $d$ ' is d-spacing, and ' $a$ ' is lattice constant. The calculated values are listed in Table 1 . The average crystallite size $(D)$ of all synthesized samples was determined by using the well-known Debye-Scherer Formula [39,40]:

$$
D=\frac{K \lambda}{\beta \cos \theta}
$$

Table 1. Structural parameters of grown samples.

\begin{tabular}{cccccccc}
\hline Samples & $\mathbf{a}(\AA)$ & $\mathbf{b}(\AA)$ & $\mathbf{c}(\AA)$ & $\mathbf{d}$-Spacing & Volume $\left(\AA^{3}\right)$ & $\begin{array}{c}\text { Crystallite } \\
\text { Size }(\mathbf{n m})\end{array}$ & $\begin{array}{c}\text { Dislocation Density } \\
\boldsymbol{\delta}(\mathbf{n m})^{-\mathbf{2}} \times \mathbf{1 0}^{-\mathbf{4}}\end{array}$ \\
\hline $\mathbf{A}$ & 8.04702 & - & - & 1.8365 & 521.0805 & 50 & 4.000 \\
$\mathbf{B}$ & 8.07016 & - & - & 1.9657 & 525.5884 & 59 & 2.870 \\
$\mathbf{C}$ & 8.06895 & - & - & 1.8362 & 525.3527 & 49 & 4.160 \\
\hline
\end{tabular}

In these equations $K$ is the shape factor having value (0.94), $\lambda$ is the wavelength of X-ray (1.5406 $\AA$ ), $\beta$ is the full width at half maxima. From the results, it can be concluded that the crystallite size follows the trend $b(59 \mathrm{~nm})>\mathrm{a}(50 \mathrm{~nm})>\mathrm{c}(49 \mathrm{~nm})$ (Table 1$)$. The dislocation density $(\delta)$ and d-spacing can be calculated by:

$$
\begin{gathered}
\delta=1 / D^{2} \\
2 d \sin \theta=n \lambda
\end{gathered}
$$

where ' $\lambda$ ' is the wavelength of X-rays in $\AA$, ' $\theta$ ' is the diffraction angle (Bragg angle) in degrees, $n$ is the order of diffraction which is the spacing between adjacent crystal planes. The calculated values are listed in Table 1 . The results show that d-spacing varies directly with crystallite size while dislocation density varies as square inverse of crystallite size.

Furthermore, compound microscopy results (Figure 5a-c) show that changing the nature of the solvent influenced on the shape of $\mathrm{Co}_{3} \mathrm{O}_{4}$ NPs. Figure 5 a shows bead-shaped $\mathrm{Co}_{3} \mathrm{O}_{4} \mathrm{NPs}$ obtained using methanol solvent extract as reducing agent [41] while in Figure $5 \mathrm{~b}$ the shape of $\mathrm{Co}_{3} \mathrm{O}_{4} \mathrm{NPs}$ obtained with hexane was different because of the different biomolecules present as compared to methanol solvent [42]. In the case of a mixed ratio of methanol and hexane solvents (Figure 5c), the $\mathrm{Co}_{3} \mathrm{O}_{4}$ NPs were cube-shaped, most probably because of the action of different active biomolecules in this fraction when they reduce the cobalt nanoparticles $[27,43]$.

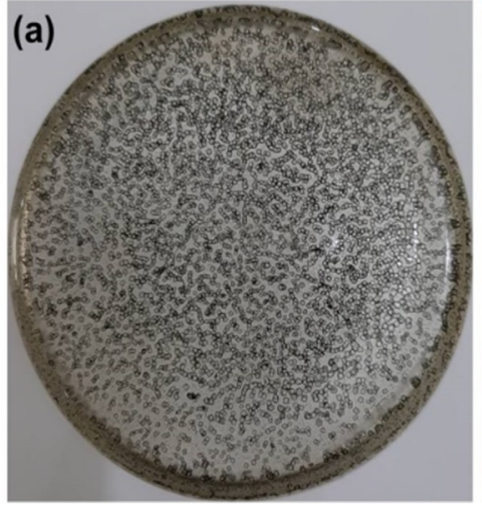

Bead shaped $\mathrm{Co}_{3} \mathrm{O}_{4} \mathrm{NPs}$ methanol fraction

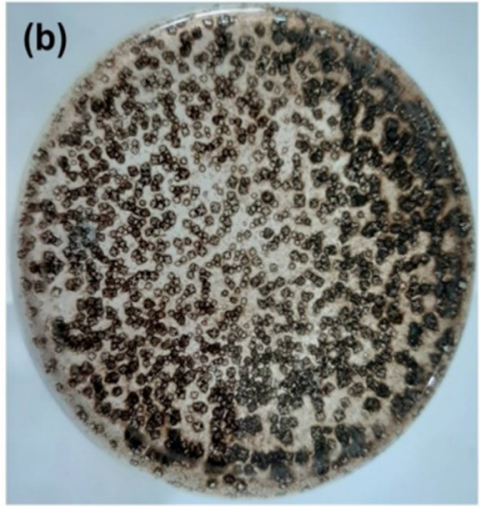

Crystal shaped $\mathrm{Co}_{3} \mathrm{O}_{4}$ NPs hexane fraction

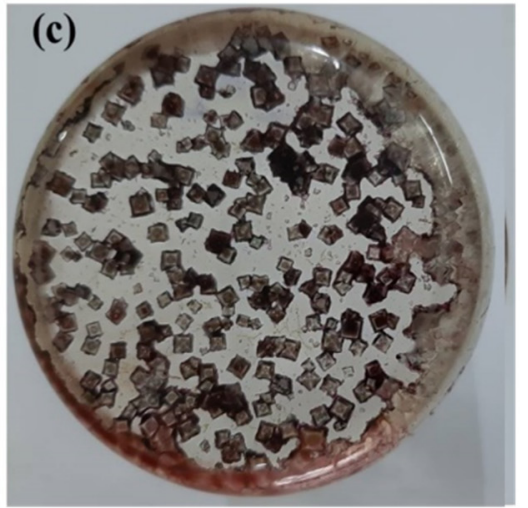

Cube shaped $\mathrm{Co}_{3} \mathrm{O}_{4} \mathrm{NPs}$ methanol/ hexane fraction

Figure 5. Variation in $\mathrm{Co}_{3} \mathrm{O}_{4}$ nanoparticle shape based on solvent fractions: (a) methanol fraction (b) hexane fraction, (c) methanol/hexane fraction.

From the above results, we can conclude that the active biomolecules exhibiting reducing potential found in the methanol/hexane fraction were proven to have the best bioreducing potential in the 
synthesis of $\mathrm{Co}_{3} \mathrm{O}_{4}$ NPs. Among the different fractional concentrations of similar solvents $30 \%$ fraction showed the best bioreducing efficiency. This means that when preparing fractions with these three solvents, and running a separate solvent fraction-based reaction, the $30 \%$ fraction will provide more significant results as previously reported [44,45]. It shows a well-defined sharp peak for every solvent containing a 30\% solvent faction. The exposed binding sites for the binding of cobalt precursors and saturating the metal by biochemical agents in order to provide stability was done by solvent-based fractionation of Withania extract as reported earlier [46].

The scheme (Figure 1) shows a double dip strategy where the nature and concentration of a solvent reduce the complexity, provide active sites and finally highlight the functional activity of the biomolecules. This solvent fractionation actually works similarly to an enzyme substrate reaction, as active sites are provided as product gets generated. Here the fractionation helps expose and present the active sites by reducing the complexity and generating $\mathrm{Co}_{3} \mathrm{O}_{4} \mathrm{NPs}$. In the next level of optimization, the concentration was kept constant and the solvent was altered. The results showed that the mixture of methanol/hexane was a hybrid solvent that reinforced the characteristic properties of each solvents. Conclusively in order to optimize our study, mixtures of methanol/hexane, at all concentrations provide the best reduction capacity. Thus, to reduce complexity, unlocking the bioactive molecules in methanol/hexane mixtures of 30\% fraction should provide an excellent lead for identifying compounds good at reducing cobalt to $\mathrm{Co}_{3} \mathrm{O}_{4}$ NPs.

\subsection{Biofilm Activity of Prepared W. coagulans Fractions}

Bioactive fractions from $W$. coagulans (12 different fractions) were evaluated for antibiofilm activity against the drug sensitive strains Pseudomonas aeruginosa and Staphylococcus aureus in 96 well micro-titer plates. The purpose was to evaluate the potential of the 12 different fractions to inhibit the growth of a preformed biofilm already established in the wells of the micro-titer plate [47]. In anti-biofilm assay biofilm was induced to grow on 96 well micro-titer plates by adding $100 \mu \mathrm{L}$ nutrient broth, $100 \mu \mathrm{L}$ plant extract and $20,100 \mu \mathrm{L}$ bacterial culture in each well and incubating for $24 \mathrm{~h}$ at $37^{\circ} \mathrm{C}$ then staining the next day with crystal violet (dye) give a dark blue color to the well where biofilm formation took place (Figure S3). Crystal violet is a dye that binds non-specifically to negatively charged surface molecules such as the polysaccharide matrix of biofilms and stains them with a blue color so it is generally used to estimate biofilm biomass [48], so a reduction in blue color indicates biofilm inhibition by different tested plant fractions.

\subsection{Antibiotic Selectivity}

First an effective positive control for P. aeruginosa and S. aureus (drug sensitive strains) was established by treating with four different antibiotics (clindamycin, moxifloxacin, penicillin and ciprofloxacin). The results showed that moxifloxacin and ciprofloxacin were more active drugs against the $P$. aeruginosa strain as indicated by a larger zone of inhibition shown by the drugs (Figure 6a,b) but ciprofloxacin was a more effective antibiotic against $S$. aureus as shown by its larger inhibition zone (Figure 6c). Thus, the strong antibiotic ciprofloxacin was selected to test the W. coagulans-based 12 different fractions of methanol and hexane and their mixtures to evaluate the biofilm inhibition potential against $P$. aeruginosa and $S$. aureus at concentrations of $5 \mathrm{mg} / \mathrm{mL}$ and $100 \mathrm{mg} / \mathrm{mL}$. 


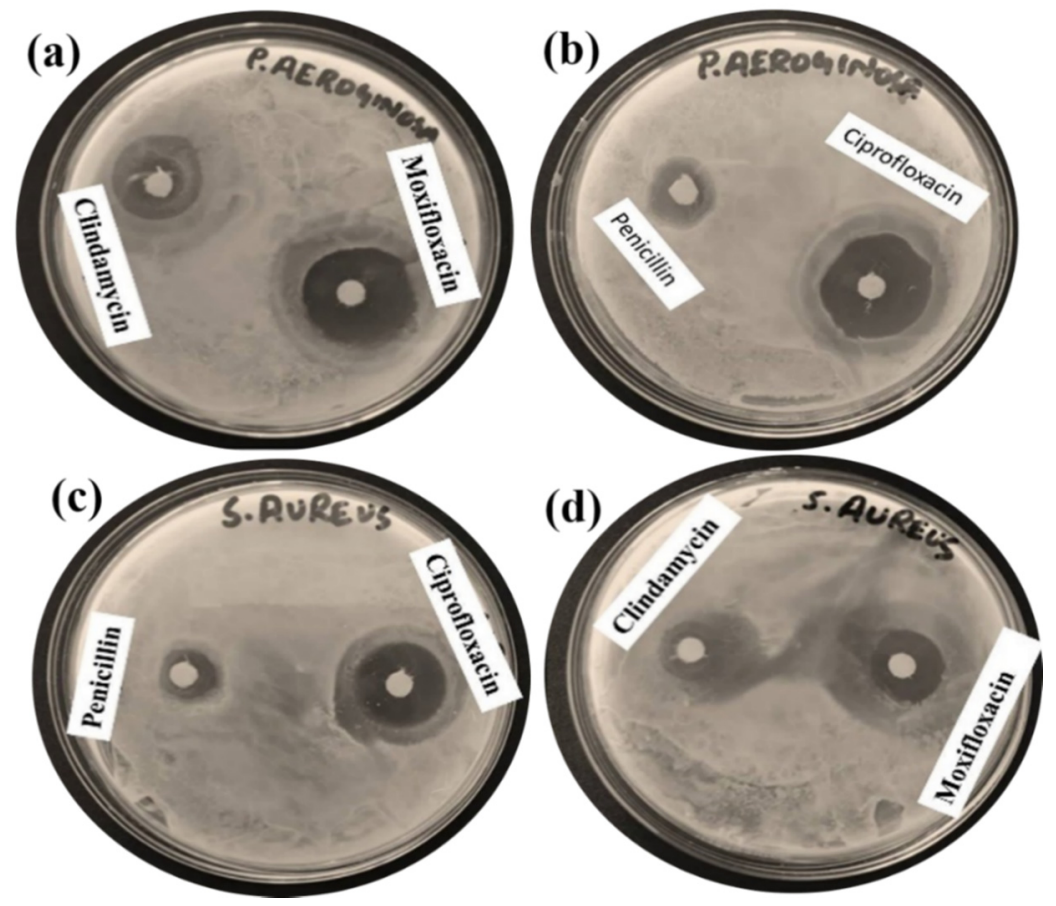

Figure 6. Antibiotic selectivity of (a) clindamycin, moxifloxacin (b) penicillin, ciprofloxacin against $P$. aeruginosa (c) penicillin, ciprofloxacin (d) clindamycin, moxifloxacin against S. aureus.

\subsubsection{Biofilm Inhibition Potential of $W$. coagulans Fraction against P. aeruginosa}

Ciprofloxacin, being a positive control against $P$. aeruginosa, shows a reduction of dark blue color of the dye (crystal violet) in the first well and solvent blank without bacterial strain marked as first negative control that does not contain bacteria so no biofilm formation occurred there, thus no crystal violet dye staining was observed (Figure S3), leaving a colorless well indicating the absence of bio-film formation. As a second negative control a well was loaded with $55 \mathrm{mg} / \mathrm{mL}$ of P. aeruginosa without the plant extract and blue colored biofilm was observed. Color reduction of the dark blue dye in the micro-titer plate well gave a rapid qualitative analysis of biofilm inhibition potential by the crystal violet staining technique that was measured as a percentage inhibition of biofilm formation. With the positive control, ciprofloxacin, the percentage inhibition against $P$. aeruginosa was found to be $50 \%$, and it was $0.7 \%$ with the negative control.

After running the successful controls, the Withania-derived solvent-based fractions were assessed. For 30\% methanol (Meth. ${ }^{\mathrm{I}}$ ) the inhibition was $0.6 \%$, for $50 \%$ methanol (Meth. ${ }^{\mathrm{II}}$ ) it was $0.5 \%$, for $70 \%$ methanol (Meth. ${ }^{\text {III }}$ ) it was $29 \%$ and for $90 \%$ methanol (Meth. ${ }^{\text {IV }}$ ) the inhibition reached $50 \%$. Hexane was next and 30\% hexane (Hex. ${ }^{\mathrm{I}}$ ) exhibited $29 \%$ inhibition, $50 \%$ hexane (Hex. ${ }^{\mathrm{II}}$ ) showed $30 \%$ inhibition, $70 \%$ hexane (Hex. ${ }^{\mathrm{III}}$ ) showed $31 \%$ and $90 \%$ hexane $\left(\mathrm{Hex}^{\mathrm{IV}}\right.$ ) gave about $24 \%$ inhibition.

The third series includes mixtures of methanol and hexane, among which 30\% methanol-hexane $\left(\mathrm{M}-\mathrm{H}^{\mathrm{I}}\right)$ showed $49 \%$ inhibition, 50\% methanol-hexane $\left(\mathrm{M}-\mathrm{H}^{\mathrm{II}}\right)$ 43\%, 70\% methanol-hexane $\left(\mathrm{M}-\mathrm{H}^{\mathrm{III}}\right)$ $42 \%$ and $90 \%$ methanol-hexane $\left(\mathrm{M}-\mathrm{H}^{\mathrm{IV}}\right)$ showed only $20 \%$ inhibition of biofilm formation. Overall Meth. ${ }^{\text {IV }}$ exhibited a $100 \%$ percentage inhibition of biofilm production with respect to control. On average Meth. inhibited $40 \%$, Hex. inhibited $57 \%$ and methanol-hexane mixture inhibited $77 \%$ with respect to control. Hence the solvent mixture super-combination showed superior results on average at all concentrations by decoding the complexity with the hybrid mixture of solvents. Biofilm formation by dye degradation and calculated inhibitions are shown in Figure 7a. These results are relevant to previous work done using plant extracts against the biofilm activity [49]. 
a)

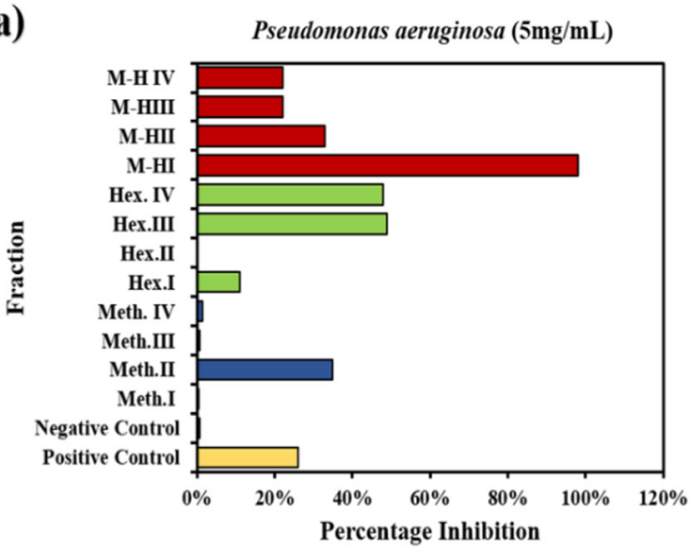

b)

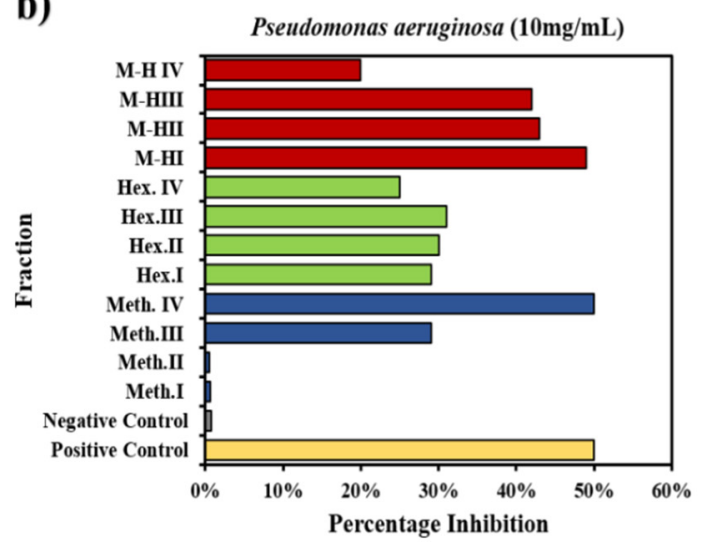

Figure 7. Biofilm activity of $W$. coagulans 12 fraction against $P$. aeruginosa with concentration (a) $5 \mathrm{mg} / \mathrm{mL}$

(b) $10 \mathrm{mg} / \mathrm{mL}$.

Similarly, when using the $10 \mathrm{mg} / \mathrm{mL}$ extract against $P$. aeruginosa where the positive control showed $26 \%$ inhibition of biofilm and $0.7 \%$ of inhibition for the negative control, $0.5 \%>35 \%>0.6 \%>1.5 \%$ inhibition was seen for Meth. ${ }^{\mathrm{I}}>$ Meth. ${ }^{\mathrm{II}}>$ Meth. ${ }^{\mathrm{III}}>$ Meth. ${ }^{\mathrm{IV}}$. Moving to the next solvent fraction Hex. ${ }^{\mathrm{I}}>$ Hex. ${ }^{\mathrm{II}}>$ Hex. ${ }^{\mathrm{III}}>\mathrm{Hex}^{\mathrm{IV}}(11 \%>0.3 \%>49 \%>48 \%)$ and lastly, for the mixture fraction $\mathrm{M}-\mathrm{H}^{\mathrm{I}}>\mathrm{M}-\mathrm{H}^{\mathrm{II}}>\mathrm{M}-\mathrm{H}^{\mathrm{III}}>\mathrm{M}-\mathrm{H}^{\mathrm{IV}}(98 \%>33 \%>22 \%)$ as depicted in Figure $6 \mathrm{~b}$ along with biofilm formation (Figure S4). The best fractions $\mathrm{M}-\mathrm{H}^{\mathrm{I}}$, Hex. ${ }^{\mathrm{III}}$, Hex. ${ }^{\mathrm{IV}}$, Meth. ${ }^{\mathrm{II}}$ and $\mathrm{M}-\mathrm{H}^{\mathrm{II}}$ provided an outstanding inhibition representing 277\%, 88\%, 85\%, 34\% and 26\% more than the control. As a result, Meth provided $36 \%$ inhibition with respect to control, Hex exhibited $4 \%$ more inhibition with respect to control whereas the excelling $\mathrm{M}-\mathrm{H}$ mixture exhibited $68 \%$ more inhibition with respect to the control on average. Some fractions had previously shown significant inhibition with $5 \mathrm{mg} / \mathrm{mL}$ Withania solution against $P$. aeruginosa [50] but changing the concentration to $100 \mathrm{mg} / \mathrm{mL}$ the bio-film percentage inhibition increased even above the control level, showing higher antibacterial activity as shown in Figure 7b.

\subsubsection{Biofilm Inhibition Potential of W. coagulans Fractions against S. aureus}

The activity of concentrations of each fraction up to $10 \mathrm{mg} / \mathrm{mL}$ against $S$. aureus was observed. Biofilm formation against $S$. aureus strain was done with ciprofloxacin as positive control which was found to be active against the drug sensitive $S$. aureus strain as shown by the white colour of wells. A negative control was also added (Figure S5).

The controls gave $55 \%$ and $0.4 \%$ inhibition, respectively. For the other 12 fractions a concentration of $55 \mathrm{~g} / \mathrm{mL}$ was used that provided no significant or results as shown in Figure 8a where the positive control inhibition was 55\% and that of the negative control was $0.4 \%$. Meth. ${ }^{\mathrm{I}}>$ Meth. ${ }^{\mathrm{II}}>$ Meth. ${ }^{\mathrm{III}}>$ Meth. ${ }^{\mathrm{IV}}$

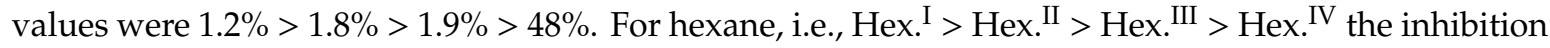
was $3.1 \%>36 \%>2.1 \%>3.2 \%$ and for mixtures $\mathrm{M}-\mathrm{H}^{\mathrm{I}}>\mathrm{M}-\mathrm{H}^{\mathrm{II}}>\mathrm{M}-\mathrm{H}^{\mathrm{III}}>\mathrm{M}-\mathrm{H}^{\mathrm{IV}}$, percentage inhibitions of $0.8 \%>20 \%>17.5 \%>12.5 \%$ were exhibited which were quite insignificant against such a resistant strain and at a such minute concentration.

Next the change in concentration up to $10 \mathrm{mg} / \mathrm{mL}$ against $S$. aureus showed significant results, whereby the positive control showed $40 \%$ inhibition and the negative one showed $0 \%$ inhibition. In the first fraction series Meth. ${ }^{\mathrm{I}}>$ Meth. ${ }^{\mathrm{II}}>$ Meth. ${ }^{\mathrm{II}}>$ Meth. ${ }^{\text {IV }}$ the inhibition was $71 \%>65 \%>28 \%>24 \%$. For hexane fractions, i.e., Hex. ${ }^{\text {I }}>\mathrm{Hex}^{\mathrm{II}}>\mathrm{Hex}^{\mathrm{II}}>\mathrm{Hex}{ }^{\mathrm{IV}}$ the results showed $3.5 \%>20 \%>19 \%>3.7 \%$ inhibition and the percentage inhibition was calculated as $2.7 \%>62 \%>72 \%>72 \%$ for $\mathrm{M}-\mathrm{H}^{\mathrm{I}}>\mathrm{M}-\mathrm{H}^{\mathrm{II}}>\mathrm{M}-\mathrm{H}^{\mathrm{III}}>\mathrm{M}-\mathrm{H}^{\mathrm{IV}}$ as shown in Figure $8 \mathrm{~b}$. Compared to the control M-H ${ }^{\mathrm{III}}>\mathrm{M}-\mathrm{H}^{\mathrm{IV}}>$ Meth. ${ }^{\mathrm{I}}>$ Meth. ${ }^{\mathrm{II}}>\mathrm{M}-\mathrm{H}^{\mathrm{II}}$ exhibited $80 \%>80 \%>78 \%>62 \%>55 \%$ more biofilm formation indicating an outstanding result at the particular dilutions that revealed the presence of antibacterial biomolecules in such fractions. On average Meth. showed 18\% more inhibition, 
Hex. showed only $28 \%$ inhibition with respect to control and $\mathrm{M}-\mathrm{H}$ was superior, exhibiting more film formation with $30 \%$ inhibition. The present observations regarding bacterial biofilm formation match the work rewported by previous researchers [51].
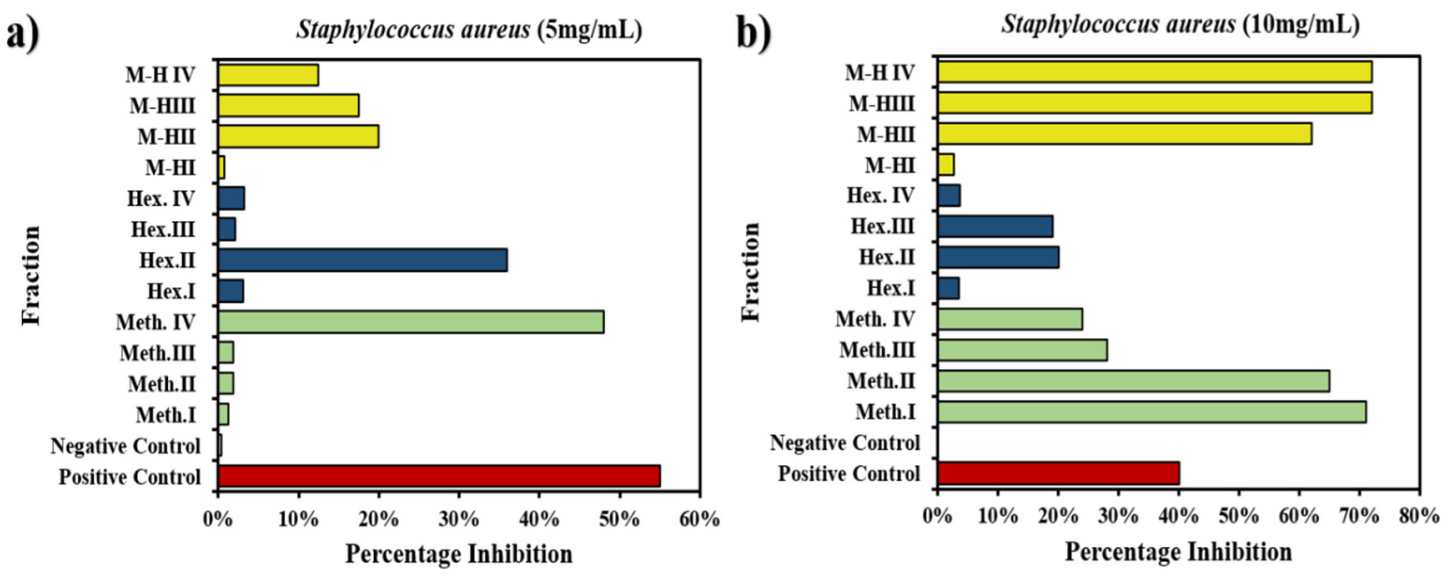

Figure 8. Biofilm activity of $W$. coagulans 12 fraction against $S$. aureus with concentration (a) $5 \mathrm{mg} / \mathrm{mL}$ (b) $10 \mathrm{mg} / \mathrm{mL}$.

\subsection{Antifungal Activity of Prepared W. coagulans Fractions}

\subsubsection{Antifungal Activity of Prepared W. coagulans against A. Niger}

The antifungal activity was evaluated using all 12 different fractions extracts of methanol and hexane and their mixtures using plant extract of $W$. coagulans against $A$. niger and $C$. albicans by the disc method [52]. The active biomolecules were resolved into simple $W$. coagulans plant molecules that exhibited antifungal activity. The active principal molecules were measure and made visible by the zone of inhibition produced by the fraction molecules against the specific strains (Figure 9a-h).
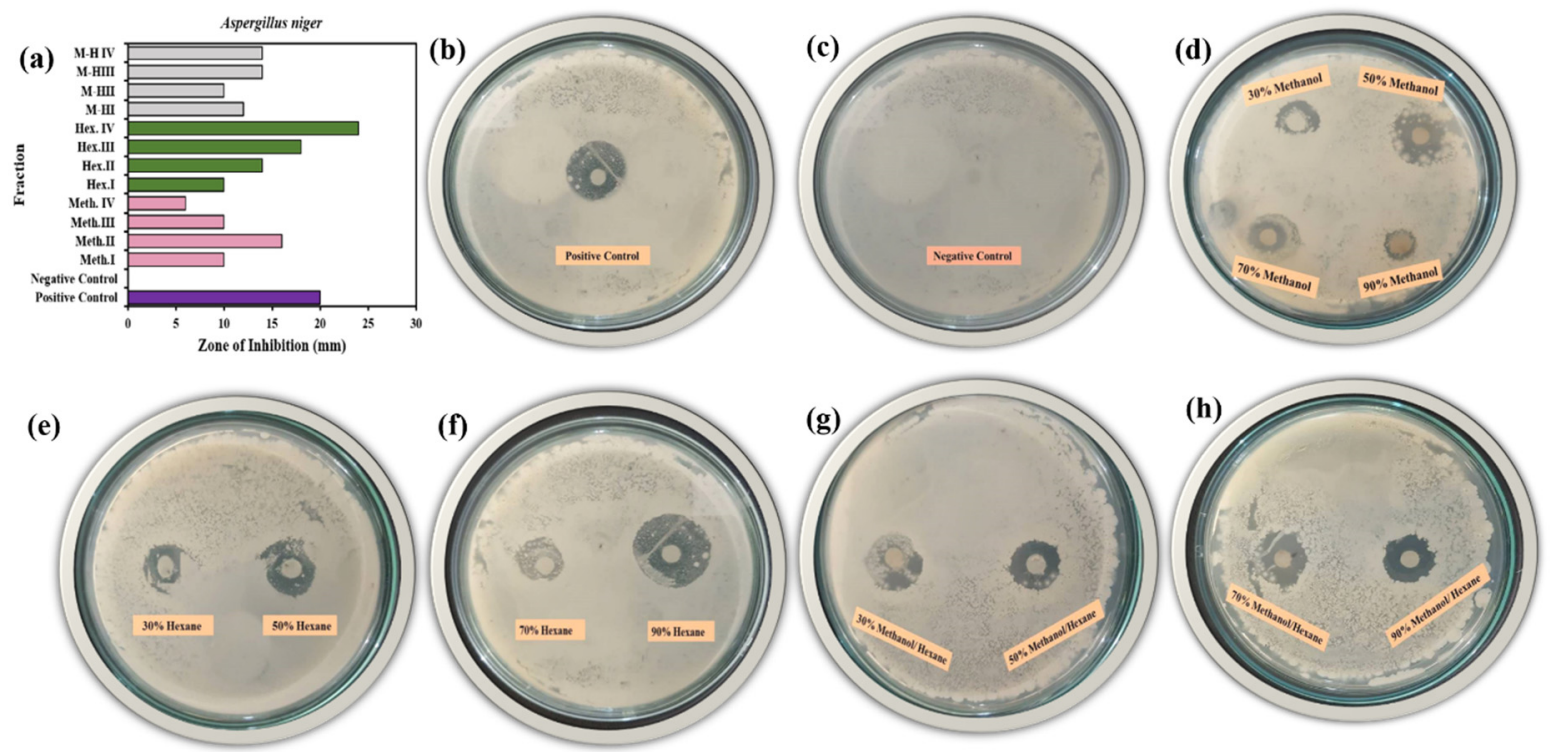

Figure 9. Antifungal activity of $12 \mathrm{~W}$. coagulans fractions against $A$. niger measured by zone of inhibition: (a) Positive control; (b) negative control; (c) methanol fractions; (d) hexane fraction 30\%, 50\%; (e) hexane fraction $70 \%, 90 \%$; (f) methanol/hexane fraction 30\%, 50\% (g); methanol/hexane fraction 70\%, 90\% (h).

The tested fractions provided significant results as follows: amphotericin B at concentration (10 mg/mL) was used as standard for both fungus strains that were pathogenic [53]. The positive 
control shows good antifungal activity against $A$. niger as indicated by the large clear inhibition zone $(20 \mathrm{~mm})$ whereas the negative control exhibited no clear zone of inhibition as shown in Figure $9 b, c$. The tested concentrations beginning with Meth. ${ }^{\mathrm{I}}>$ Meth. ${ }^{\mathrm{II}}>$ Meth. ${ }^{\mathrm{III}}>$ Meth. ${ }^{\mathrm{IV}}$ exhibited $10 \mathrm{~mm}>16 \mathrm{~mm}>10 \mathrm{~mm}>6 \mathrm{~mm}$ inhibition, with an average of $50 \%$ antifungal activity compared to the control (Figure 9d). Next is the hexane fractions, Hex. ${ }^{\mathrm{I}}>$ Hex. ${ }^{\mathrm{II}}>$ Hex. ${ }^{\mathrm{III}}>$ Hex. ${ }^{\mathrm{IV}}$ showing $10 \mathrm{~mm}>14 \mathrm{~mm}>18 \mathrm{~mm}>24 \mathrm{~mm}$ zone of inhibition with $83 \%$ agreement with the control (Figure 9e,f). Finally $\mathrm{M}-\mathrm{H}^{\mathrm{I}}>\mathrm{M}-\mathrm{H}^{\mathrm{II}}>\mathrm{M}-\mathrm{H}^{\mathrm{III}}>\mathrm{M}-\mathrm{H}^{\mathrm{IV}}$ where the zone of inhibition provided $62 \%$ similar result on average with control and $12 \mathrm{~mm}>10 \mathrm{~mm}>14 \mathrm{~mm}>14 \mathrm{~mm}$ inhibition zones, respectively (Figure $9 \mathrm{~g}, \mathrm{~h}$ ). Surprisingly Hex. ${ }^{\mathrm{V}}$ showed $20 \%$ more antifungal activity than the control against $A$. niger.

\subsubsection{Antifungal Activity of Prepared W. coagulans against C. albicans}

C. albicans showed a $20 \mathrm{~mm}$ zone of inhibition with the positive control amphotericin $\mathrm{B}$, an effective drug against this strain (Figure 10a-h). The negative control provided no zone of inhibition indicating no antifungal activity (Figure 10c). On further treatment the 12 fractions provided significant results, where Meth. provided $6 \%$ antifungal activity, Hex. $70 \%$ activity and $\mathrm{M}-\mathrm{H} 83 \%$ activity with respect to the control.
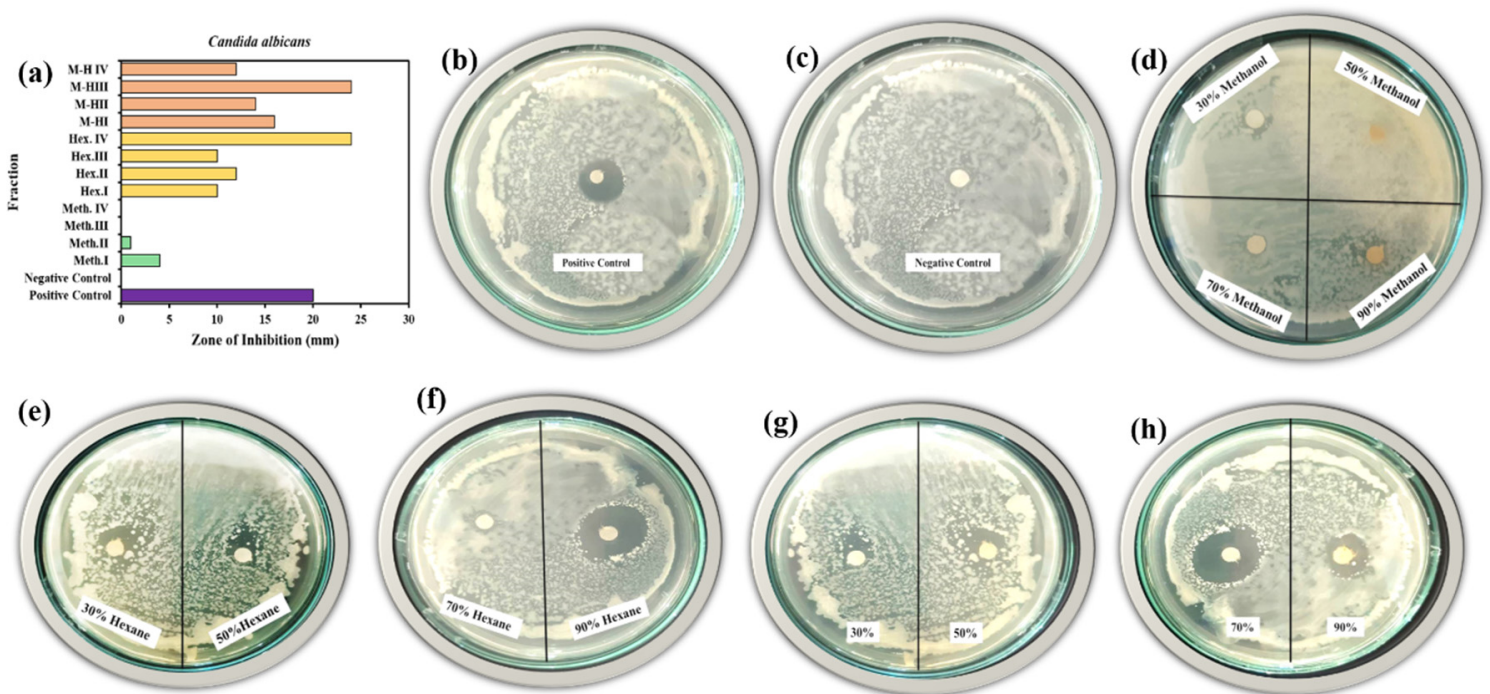

Figure 10. Antifungal activity of 12 W. coagulans fractions against C. albicans (zone of inhibition): (a) Positive control (b) negative control (c) methanol fractions (d) hexane fraction 30\%, 50\% (e) hexane fraction $70 \%, 90 \%$ (f) methanol/hexane fraction 30\%, 50\% (g) methanol/hexane fraction 70\%, 90\% (h).

Individually Meth. ${ }^{\mathrm{I}}>$ Meth. ${ }^{\mathrm{II}}>$ Meth. ${ }^{\mathrm{III}}>$ Meth. $^{\mathrm{IV}}$ provided $4 \mathrm{~mm}>1 \mathrm{~mm}>0 \mathrm{~mm}>0 \mathrm{~mm}$ of inhibition zone (Figure 10d), Hex. ${ }^{\mathrm{I}}>\mathrm{Hex} .^{\mathrm{II}}>\mathrm{Hex} .{ }^{\mathrm{III}}>\mathrm{Hex}{ }^{\mathrm{IV}}$ had $10 \mathrm{~mm}>12 \mathrm{~mm}>10 \mathrm{~mm}>24 \mathrm{~mm}$ inhibition (Figure 10e,f). Finally $16 \mathrm{~mm}>14 \mathrm{~mm}>24 \mathrm{~mm}>12 \mathrm{~mm}$ zones of inhibition were measured for $\mathrm{M}-\mathrm{H}^{\mathrm{I}}>\mathrm{M}-\mathrm{H}^{\mathrm{II}}>\mathrm{M}-\mathrm{H}^{\mathrm{III}}>\mathrm{M}-\mathrm{H}^{\mathrm{IV}}$ fractions (Figure 10g,h). With C. albicans Hex. ${ }^{\mathrm{IV}}$ and $\mathrm{M}-\mathrm{H}^{\mathrm{III}}$ exhibited $20 \%$ more antifungal activity that the control.

The antibacterial and antifungal activity using $W$. coagulans was proven to be significant because of the biomolecules initially present in complex form that were resolved into simple and more functionally active groups by the solvent-based fractionation method. Owing to such a strategy and the significant activity this set of optimizations can be incorporated in the medicinal field in order to combat bacterial and fungal infections. Plant extracts have shown a variety of potentials such as reducing, antioxidant, synthetic, and medicinal activities due to the presence of numerous bio-molecules that exist in different parts of the plant. Depending upon the nature each show different extents of variation in their capabilities due to the presence of some additional biomolecules and the varying concentrations of those biomolecules. Considering Withani, it is truly rich in phenols, flavonoids, alkaloids, steroids and 
other complex structures that provide reducing, antibacterial and antifungal activities. The results of this work show that the separation of these components using different solvents such as water, hexane, methanol, acetone, etc., enhanced the activities by aiding in resolving the complexity, dissolving components of different nature according to their solubility in different solvents, combining the biomolecules for effective interaction and thus showing their potentials at their maximum level. Similarly, Withania had shown antibacterial activity against Salmonella typhi, Klebsiella pneumonia, S. aureus with percentage antibacterial activities as $43 \%, 0 \%, 73 \%$ respectively. Withania-decorated iron rods enhanced the activity up to $30 \%$ for S. aureus and P. aeruginosa, whereas Withania showed less inhibition against a Brucella strain. Multiple examples have shown that the bacterial inhibition of crude extracts was not so high as that achieved by using solvent- based fractionation methods that enhance the values and activity to a significant level. Antifungal activity was exhibited against various strains such as A. flavus, A. niger, Penicillium and Alternaria alternate, where a significant 6-10 $\mathrm{mm}$ zone was measured. Thus, the addition of solvents, mixtures of solvents, and the concentration help in simplifying the complex structure of the plant extracts that displayed much higher activities, including bioreduction, antibacterial and antifungal properties.

\section{Materials and Methods}

\subsection{Plant Material}

Plant of W. coagulans was obtained from a local market in Bahawalpur, Pakistan in September 2018. Fresh plant was washed three time with distilled $\mathrm{H}_{2} \mathrm{O}$ and kept in the shade until it was completely dried, then it was crushed into powder form for further use.

\subsection{Preparation of Plant Extract}

Whole plant was dried and crushed using a pestle and mortar to obtain a fine powder, then $10 \mathrm{~g}$ of extract powder was dipped in different concentrations of methanol and hexane to make 12 different fractions with ratios of $90 \%, 70 \%, 50 \%, 30 \%$ (final volume $200 \mathrm{~mL}$ ). After overnight incubation the extracts were filtered and the filtrates were dried in an incubator at $37^{\circ} \mathrm{C}$. These powder extracts then used to check the bioreducing, antifungal and biofilm activities.

\subsection{Synthesis of Cobalt Oxide Nanoparticles}

For the synthesis of cobalt oxide nanoparticles, a $0.5 \mathrm{M}$ solution of cobalt chloride was prepared Flasks containing $40 \mathrm{~mL}$ cobalt chloride solution and $10 \mathrm{~mL}$ plant extract $(90 \%, 70 \%, 50 \%, 30 \%)$ were prepared, put on a magnetic stirrer $(150 \mathrm{rpm})$ and kept there for $4 \mathrm{~h}$ at $90{ }^{\circ} \mathrm{C}$ as a reaction occurred indicated by a change in color confirming the synthesis of nanoparticles. After this the mixture was centrifuged at $6000 \mathrm{rpm}$ for $10 \mathrm{~min}$., the pellet was separated and dried for characterization.

\subsection{UV-Vis Spectroscopy}

All 12 fractions were subjected to UV-Vis spectroscopy (Instrument model VT05404-0998, Biotek, Winooski, VT, USA) at predetermined time intervals to confirm the formation of cobalt nanoparticles and the wavelength was noted. Peaks between $550-510 \mathrm{~nm}$ give a positive indication of nanoparticle synthesis. Also, the color changes of reaction mixtures were used as evidence of cobalt oxide nanoparticle formation

\subsection{Morphology Analysis of via Compound Microscope}

The dried form of the cobalt oxide nanoparticles was uniformly distributed in Petri plates with relevant solvent and allowed to dry. Later compound microscopy (model IM-850, IRMECO GmbH, Hamburg, Germany) was used to observe the morphological variations in all three fractions. 


\subsection{Biofilm Assay of W. coagulans Fraction}

Biofilm assays were performed by a crystal violet staining assay. The effect of extracts on biofilm formation was evaluated in 96-well polystyrene plates. Firstly, the 96-well micro-titer plates were washed with sterile distilled water, air dried and then oven-dried at $60{ }^{\circ} \mathrm{C}$ for $45 \mathrm{~min}$. Briefly, nutrient broth, standard drug (ciprofloxacin) and bacterial culture were used as positive control while nutrient broth, distilled water and bacterial culture were used as negative control. Nutrient broth, plant fractions and bacterial culture were added to each micro-plate and incubated at $37^{\circ} \mathrm{C}$ for $24 \mathrm{~h}$. After that staining with $0.1 \%$ crystal violet was performed and the OD was recorded at $630 \mathrm{~nm}$ using an ELISA reader (model IM-850, IRMECO GmbH, Hamburg, Germany) and \% inhibition was calculated by following formula:

$$
\% \text { inhibition }=\left(\mathrm{A}_{0}-\mathrm{A}_{1}\right) / \mathrm{A}_{0} \times 100
$$

where $A_{0}$ is absorbance of negative control and $A_{1}$ is the absorbance of the plant fractions

\subsection{Antifungal Activity of W. coagulans Fraction}

Fresh plant was washed two times with distilled water and allowed to dry at room temperature for 3 to 4 days. The dried material was ground and extracted separately by making different methanol and hexane fractions. The extracts were filtered and the filtrate was dried. All extracts fractions were stored at $4{ }^{\circ} \mathrm{C}$ and used for the bioassays. The plant extracts were tested against two important fungal pathogens, C. albicans and A. niger, obtained from the laboratory of the Department of Biochemistry and Biotechnology (Islamia University Bahawalpur). All cultures were maintained on SDA agar at $37^{\circ} \mathrm{C}$. Overnight cultures on SGA slants at $37^{\circ} \mathrm{C}$ were used to prepare the fungal inoculum to be used in the antimicrobial assays. The antifungal activity of $W$. coagulans methanolic and hexane extracts was measured according to the disc diffusion method. Sterile blank discs of $6 \mathrm{~mm}$ diameter were soaked with the prepared $W$. coagulans extracts to give a final concentration of $10 \mathrm{mg} / \mathrm{mL}$, respectively. The discs were then placed firmly on a SDA surface which has been previously seeded with C. albicans strain suspension. The same steps were repeated for the A. niger strain. All plates were incubated overnight at $37^{\circ} \mathrm{C}$. Throughout this experiment, a blank disc impregnated with sterile distilled water represented as negative control while a disc soaked with $100 \mu \mathrm{L}$ of amphotericin B was the positive control. The susceptibility of each Candida spp. was determined by the diameter of the growth inhibited zone surrounding the disc.

\section{Conclusions}

Twelve different $W$. coagulans-based fractions prepared using combinations of different solvents (methanol, hexane) and their mixture were used to study the effect of different solvent combinations on various biological activities. Plant fractions of different concentration (30\%, 50\%, 70\%, 90\%) were used. These fraction were used to investigate the bioreducing potential of the plant extracts containing complex biomolecule mixtures, it was found that collectively $30 \%$ fraction of methanol. hexane, and mixture of methanol-hexane provided the highest reducing potential for the synthesis of cobalt oxide nanoparticles. Results also showed that 90\% methanol/hexane and 30\% methanol/hexane were more active against biofilm formation of P. aeruginosa and $S$. aureus so these fractions could be used for treatment of various drug resistance-related bacterial infections. A 90\% fraction of hexane/ $\mathrm{H}_{2} \mathrm{O}$ showed excellent antifungal activity against $P$. niger and $C$. albicans, while $70 \%$ methanol/hexane show good antifungal activity for C. albicans, so these fractions are potentially useful for the treatment of various fungal infections. This solvent-based fractionation method provides a direct means to reduce the complexity of the $W$. coagulans extracts and reveal the strong bioreducing, antifungal and antibiofilm activities and optimize the particular activity for practical applications. This provides a cost-effective, ecofriendly, non-toxic and effective source for medicinal and synthetic applications. 
Supplementary Materials: The following are available online, Figure S1 Screening strategy for exploring bioactive fraction of W. coagulans; Table S1 Different solvent fractionation of Withania coagulans.

Author Contributions: Conceptualization, M.H., S.G.H. and X.S.; methodology, S.Z.; software, S.G.H.; validation, T.M., F.L. and F.I.; formal analysis, S.Z.; investigation, A.Z.; resources, T.T.; data curation, S.G.H.; writing-original draft preparation, M.H.; writing-review and editing, M.H.; visualization, X.S.; supervision, M.H.; project administration, X.S.; funding acquisition, X.S.; Experimentation, I.S. All authors have read and agreed to the published version of the manuscript.

Funding: This research received no special external funding.

Acknowledgments: The authors express their gratitude for the financial support from the Provincial Education Department Project (Natural Science, 2017KZDXM045), the Agriculture and Rural Department Project of Guangdong Province, the Guangzhou Foreign Cooperation Project (201907010033), the Graduate Technology Innovation Fund (KJCX2019004), and the Undergraduate Innovation and Entrepreneurship Training Program (S201911347028). The authors would also like to thank, The Islamia University Bahawalpur, Pakistan, National Research Program for University (NRPU) for Higher Education Commission (9458).

Conflicts of Interest: The authors declare no conflict of interest.

\section{References}

1. Blair, J.M.A.; A Webber, M.; Baylay, A.J.; Ogbolu, D.O.; Piddock, L.J.V. Molecular mechanisms of antibiotic resistance. Nat. Rev. Genet. 2014, 13, 42-51. [CrossRef] [PubMed]

2. De Kievit, T. Biofilms. Compr. Biotechnol. 2011, 1, 529-540. [CrossRef]

3. Hall-Stoodley, L.; Costerton, J.W.; Stoodley, P. Bacterial biofilms: From the Natural environment to infectious diseases. Nat. Rev. Genet. 2004, 2, 95-108. [CrossRef] [PubMed]

4. Abu Bakar, M.; McKimm, J.; Haque, S.Z.; Majumder, A.A.; Haque, M. Chronic tonsillitis and biofilms: A brief overview of treatment modalities. J. Inflamm. Res. 2018, 11, 329-337. [CrossRef]

5. Orazi, G.; Ruoff, K.L.; O'Toole, G.A.; Wright, G.; Gilmore, M. Pseudomonas aeruginosa Increases the Sensitivity of Biofilm-Grown Staphylococcus aureus to Membrane-Targeting Antiseptics and Antibiotics. mBio 2019, 10, e01501-19. [CrossRef] [PubMed]

6. Dadar, M.; Tiwari, R.; Karthik, K.; Chakraborty, S.; Shahali, Y.; Dhama, K. Candida albicans-Biology, molecular characterization, pathogenicity, and advances in diagnosis and control—An update. Microb. Pathog. 2018, 117, 128-138. [CrossRef] [PubMed]

7. Cannon, R.D.; Chaffin, W. Oral Colonization By Candida Albicans. Crit. Rev. Oral Boil. Med. 1999, 10, 359-383. [CrossRef]

8. Nyirjesy, P. Management of Persistent Vaginitis. Obstet. Gynecol. 2014, 124, 1135-1146. [CrossRef]

9. Gavaldà, J.; Meije, Y.; Fortun, J.; Roilides, E.; Saliba, F.; Lortholary, O.; Muñoz, P.; Grossi, P.; Cuenca-Estrella, M. Invasive fungal infections in solid organ transplant recipients. Clin. Microbiol. Infect. 2014, 20, 27-48. [CrossRef]

10. Kosmidis, C.; Denning, D. The clinical spectrum of pulmonary aspergillosis. Thorax 2014, 70, $270-277$. [CrossRef]

11. Slobodníková, L.; Fialová, S.; Rendeková, K.; Kováč, J.; Mučaji, P. Antibiofilm Activity of Plant Polyphenols. Molecules 2016, 21, 1717. [CrossRef]

12. Clain, E.; Haddad, J.G.; Koishi, A.C.; Sinigaglia, L.; Rachidi, W.; Despres, P.; Dos Santos, C.N.D.; Guiraud, P.; Jouvenet, N.; El Kalamouni, C.; et al. The Polyphenol-Rich Extract from Psiloxylon mauritianum, an Endemic Medicinal Plant from Reunion Island, Inhibits the Early Stages of Dengue and Zika Virus Infection. Int. J. Mol. Sci. 2019, 20, 1860. [CrossRef] [PubMed]

13. Ren, Z.; Chen, L.; Li, J.; Li, Y. Inhibition ofStreptococcus mutanspolysaccharide synthesis by molecules targeting glycosyltransferase activity. J. Oral Microbiol. 2016, 8, 623. [CrossRef] [PubMed]

14. Ichikawa, H. Withanolides potentiate apoptosis, inhibit invasion, and abolish osteoclastogenesis through suppression of nuclear factor-B (NF-B) activation and NF-B-regulated gene expression. Mol. Cancer Ther. 2006, 5, 1434-1445. [CrossRef] [PubMed]

15. Salwaan, C.; Singh, A.; Mittal, A.; Singh, P. Investigation of the Pharmacognostical, Phytochemical and Antioxidant Studies of Plant Withania coagulans Dunal. J. Pharmacogn. Phytochem. 2012, 1, 32-39.

16. Gupta, P.C. Withania coagulans Dunal-An overview. Int. J. Pharm. Sci. Rev. Res. 2012, 11, 448-451. 
17. Prasad, S.; Singh, P.; Wahi, A.; Hemalatha, S. Pharmacognostical Standardization of Withania coagulans Dunal. Pharmacogn. J. 2010, 2, 386-394. [CrossRef]

18. Ismail, H.; Rasheed, A.; Haq, I.-U.; Jafri, L.; Ullah, N.; Dilshad, E.; Sajid, M.; Mirza, B. Five Indigenous Plants of Pakistan with Antinociceptive, Anti-Inflammatory, Antidepressant, and Anticoagulant Properties in Sprague Dawley Rats. Evid.-Based Complement Altern. Med. 2017, 2017, 1-10. [CrossRef]

19. Ahmad, R.; Fatima, A.; Srivastava, A.; Khan, M.A. Evaluation of apoptotic activity of Withania coagulans methanolic extract against human breast cancer and Vero cell lines. J. Ayurveda Integr. Med. 2017, 8, 177-183. [CrossRef]

20. Maurya, R.; Akanksha; Jayendra; Singh, A.B.; Srivastava, A.K. Coagulanolide, a withanolide from Withania coagulans fruits and antihyperglycemic activity. Bioorganic Med. Chem. Lett. 2008, 18, 6534-6537. [CrossRef]

21. Gupta, V.; Keshari, B.B. Withania Coagulans Dunal. (Paneer Doda): A Review. Int. J. Ayurvedic Herb. Med. 2013, 3, 1330-1336.

22. Khodaei, M.; Jafari, M.; Noori, M. Remedial Use of Withanolides from Withania Coagolans (Stocks) Dunal. Adv. Life Sci. 2012, 2, 6-19. [CrossRef]

23. Qasim, S.; Zafar, A.; Saif, M.S.; Ali, Z.; Nazar, M.; Waqas, M.; Haq, A.U.; Tariq, T.; Hassan, S.G.; Iqbal, F.; et al. Green synthesis of iron oxide nanorods using Withania coagulans extract improved photocatalytic degradation and antimicrobial activity. J. Photochem. Photobiol. B Biol. 2020, 204, 111784. [CrossRef] [PubMed]

24. Tripathi, D.; Modi, A.; Narayan, G.; Rai, S.P. Green and cost effective synthesis of silver nanoparticles from endangered medicinal plant Withania coagulans and their potential biomedical properties. Mater. Sci. Eng. C 2019, 100, 152-164. [CrossRef] [PubMed]

25. Maurya, R.; And, A. Jayendra Chemistry and pharmacology of Withania coagulans: An Ayurvedic remedy. J. Pharm. Pharmacol. 2010, 62, 153-160. [CrossRef]

26. Yousaf, M.; Ahmad, M.; Bhatti, I.A.; Nasir, A.; Hasan, M.; Jian, X.; Kalantar-Zadeh, K.; Mahmood, N. In Vivo and In Vitro Monitoring of Amyloid Aggregation via BSA@FGQDs Multimodal Probe. ACS Sens. 2018, 4, 200-210. [CrossRef]

27. Hasan, M.; Zafar, A.; Yousaf, M.; Gulzar, H.; Mehmood, K.; Hassan, S.G.; Saeed, A.; Yousaf, A.; Mazher, A.; Rongji, D.; et al. Synthesis of Loureirin B-Loaded Nanoliposomes for Pharmacokinetics in Rat Plasma. ACS Omega 2019, 4, 6914-6922. [CrossRef]

28. Kim, S.; Yu, J.S.; Lee, J.Y.; Choi, S.U.; Lee, J.; Kim, K.H. Cytotoxic Withanolides from the Roots of Indian Ginseng (Withania somnifera). J. Nat. Prod. 2019, 82, 765-773. [CrossRef]

29. Kaur, A.; Singh, B.; Ohri, P.; Wang, J.; Wadhwa, R.; Kaul, S.C.; Pati, P.K.; Kaur, A. Organic cultivation of Ashwagandha with improved biomass and high content of active Withanolides: Use of Vermicompost. PLoS ONE 2018, 13, e0194314. [CrossRef]

30. Vaishnavi, K.; Saxena, N.; Shah, N.; Singh, R.; Manjunath, K.; Uthayakumar, M.; Kanaujia, S.P.; Kaul, S.C.; Sekar, K.; Wadhwa, R. Differential Activities of the Two Closely Related Withanolides, Withaferin A and Withanone: Bioinformatics and Experimental Evidences. PLoS ONE 2012, 7, e44419. [CrossRef]

31. Rai, M.K.; Jogee, P.S.; Agarkar, G.; Dos Santos, C.A. Anticancer activities of Withania somnifera: Current research, formulations, and future perspectives. Pharm. Biol. 2015, 54, 189-197. [CrossRef]

32. Yousaf, A.; Zafar, A.; Ali, M.; Bukhary, S.M.; Manzoor, Y.; Tariq, T.; Saeed, A.; Akram, M.; Bukhari, F.; Abdullah, M.; et al. Intrinsic Bio-Enhancer Entities of Fagonia cretica for Synthesis of Silver Nanoparticles Involves Anti-Urease, Anti-Oxidant and Anti-Tyosinase Activity. Adv. Biosci. Biotechnol. 2019, 10, 455-468. [CrossRef]

33. Zulfiqar, H.; Zafar, A.; Rasheed, M.N.; Ali, Z.; Mehmood, K.; Mazher, A.; Hasan, M.; Mahmood, N.; Ayesha, Z.; Rasheed, N. Synthesis of silver nanoparticles using Fagonia cretica and their antimicrobial activities. Nanoscale Adv. 2019, 1, 1707-1713. [CrossRef]

34. Hasan, M.; Teng, Z.; Iqbal, J.; Awan, U.; Meng, S.; Dai, R.; Qing, H.; Deng, Y. Assessment of Bioreducing and Stabilizing Potential of Dragon's Blood (Dracaena Cochinchinensis, Lour. S. C. Chen) Resin Extract in Synthesis of Silver Nanoparticles. Nanosci. Nanotechnol. Lett. 2013, 5, 780-784. [CrossRef]

35. Hasan, M.; Iqbal, J.; Awan, U.; Saeed, Y.; RanRan, Y.; Liang, Y.; Dai, R.; Deng, Y. Mechanistic Study of Silver Nanoparticle's Synthesis by Dragon's Blood Resin Ethanol Extract and Antiradiation Activity. J. Nanosci. Nanotechnol. 2015, 15, 1320-1326. [CrossRef] [PubMed] 
36. Hasan, M.; Ullah, I.; Zulfiqar, H.; Naeem, K.; Iqbal, A.; Gul, H.; Ashfaq, M.; Mahmood, N. Biological entities as chemical reactors for synthesis of nanomaterials: Progress, challenges and future perspective. Mater. Today Chem. 2018, 8, 13-28. [CrossRef]

37. Akbar, S.; Haleem, K.S.; Tauseef, I.; Rehman, W.; Ali, N.; Hasan, M. Raphanus sativus Mediated Synthesis, Characterization and Biological Evaluation of Zinc Oxide Nanoparticles. Nanosci. Nanotechnol. Lett. 2017, 9, 2005-2012. [CrossRef]

38. Mahmood, S.; Fatima, T.; Zulfaqar, H.; Saher, R.; Rafiq, M.; Rehman, A.; Dai, R.; Ashfaq, M.; Hasan, M. Meta-analysis of dragon's blood resin extract as radio-protective agent. J. Coast. Life Med. 2017, 409-416. [CrossRef]

39. Munawar, T.; Yasmeen, S.; Hasan, M.; Mahmood, K.; Hussain, A.; Ali, A.; Arshad, M.; Iqbal, F. Novel tri-phase heterostructured $\mathrm{ZnO}-\mathrm{Yb}_{2} \mathrm{O}_{3}-\mathrm{Pr}_{2} \mathrm{O}_{3}$ nanocomposite; structural, optical, photocatalytic and antibacterial studies. Ceram. Int. 2020, 46, 11101-11114. [CrossRef]

40. Munawar, T.; Yasmeen, S.; Mukhtar, F.; Nadeem, M.S.; Mahmood, K.; Saif, M.S.; Hasan, M.; Ali, A.; Hussain, F.; Iqbal, F. $\mathrm{Zn}_{0.9} \mathrm{Ce}_{0.05} \mathrm{M}_{0.05} \mathrm{O}(\mathrm{M}=\mathrm{Er}, \mathrm{Y}, \mathrm{V})$ nanocrystals: Structural and energy bandgap engineering of $\mathrm{ZnO}$ for enhancing photocatalytic and antibacterial activity. Ceram. Int. 2020, 46, 14369-14383. [CrossRef]

41. Fathalipour, S.; Pourbeyram, S.; Sharafian, A.; Tanomand, A.; Azam, P. Biomolecule-assisted synthesis of $\mathrm{Ag} /$ reduced graphene oxide nanocomposite with excellent electrocatalytic and antibacterial performance. Mater. Sci. Eng. C 2017, 75, 742-751. [CrossRef] [PubMed]

42. Somu, P.; Paul, S.; S, P. A biomolecule-assisted one-pot synthesis of zinc oxide nanoparticles and its bioconjugate with curcumin for potential multifaceted therapeutic applications. New J. Chem. 2019, 43, 11934-11948. [CrossRef]

43. Hasan, M.; Iqbal, J.; Awan, U.; Xin, N.; Dang, H.; Waryani, B.; Saeed, Y.; Ullah, K.; Rongji, D.; Deng, Y. LX loaded nanoliposomes synthesis, characterization and cellular uptake studies in $\mathrm{H}_{2} \mathrm{O}_{2}$ stressed SH-SY5Y cells. J. Nanosci. Nanotechnol. 2014, 14, 4066-4071. [CrossRef] [PubMed]

44. Ran, Y.; Wang, R.; Hasan, M.; Jia, Q.; Tang, B.; Shan, S.; Deng, Y.; Qing, H. Radioprotective effects of dragon's blood and its extracts on radiation-induced myelosuppressive mice. J. Ethnopharmacol. 2014, 154, 624-634. [CrossRef] [PubMed]

45. Ran, Y.; Wang, R.; Gao, Q.; Jia, Q.; Hasan, M.; Awan, M.U.F.; Tang, B.; Zhou, R.; Dong, Y.; Wang, X.; et al. Dragon's blood and its extracts attenuate radiation-induced oxidative stress in mice. J. Radiat. Res. 2014, 55, 699-706. [CrossRef]

46. Ran, Y.; Wang, R.; Lin, F.; Hasan, M.; Jia, Q.; Tang, B.; Xia, Y.; Shan, S.; Wang, X.; Li, Q.; et al. Radioprotective effects of Dragon's blood and its extract against gamma irradiation in mouse bone marrow cells. Phys. Med. 2014, 30, 427-431. [CrossRef] [PubMed]

47. Petrachi, T.; Resca, E.; Piccinno, M.S.; Biagi, F.; Strusi, V.; Dominici, M.; Veronesi, E. An Alternative Approach to Investigate Biofilm in Medical Devices: A Feasibility Study. Int. J. Environ. Res. Public Health 2017, 14, 1587. [CrossRef]

48. Good, M.; Wend, C.; Bond, L.; McLean, J.S.; Panetta, P.; Ahmed, S.; Crawford, S.; Daly, D. An estimate of biofilm properties using an acoustic microscope. IEEE Trans. Ultrason. Ferroelectr. Freq. Control 2006, 53, 1637-1648. [CrossRef]

49. Biswas, B.; Rogers, K.; McLaughlin, F.; Daniels, D.; Yadav, A. Antimicrobial Activities of Leaf Extracts of Guava (Psidium guajavaL.) on Two Gram-Negative and Gram-Positive Bacteria. Int. J. Microbiol. 2013, 2013, 1-7. [CrossRef]

50. Türeli, N.G.; Torge, A.; Juntke, J.; Schwarz, B.C.; Schneider-Daum, N.; Türeli, A.E.; Lehr, C.-M.; Schneider, M. Ciprofloxacin-loaded PLGA nanoparticles against cystic fibrosis P. aeruginosa lung infections. Eur. J. Pharm. Biopharm. 2017, 117, 363-371. [CrossRef]

51. Manandhar, S.; Luitel, S.; Dahal, R.K. In Vitro Antimicrobial Activity of Some Medicinal Plants against Human Pathogenic Bacteria. J. Trop. Med. 2019, 2019, 1895340-5. [CrossRef] 
52. Samadi, F.M.; Suhail, S.; Sonam, M.; Sharma, N.; Singh, S.; Gupta, S.; Dobhal, A.; Pradhan, H. Antifungal efficacy of herbs. J. Oral Biol. Craniofacial Res. 2018, 9, 28-32. [CrossRef] [PubMed]

53. Hamill, R.J. Amphotericin B Formulations: A Comparative Review of Efficacy and Toxicity. Drugs 2013, 73, 919-934. [CrossRef] [PubMed]

Sample Availability: Samples of the compounds are available from the authors.

(C) 2020 by the authors. Licensee MDPI, Basel, Switzerland. This article is an open access article distributed under the terms and conditions of the Creative Commons Attribution (CC BY) license (http://creativecommons.org/licenses/by/4.0/). 